\title{
Perfil hidroambiental como ferramenta na avaliação da condição da qualidade de águas superficiais no contexto de microbacias
}

\section{Hydroenvironmental profile as a tool for assessing the condition of water quality in the micro river basin context}

\author{
Cleiton Oliveira dos Santos \\ Mestre em Tecnologias Ambientais, UFMS \\ Docente do curso de Gestão Ambiental, Universidade Estadual de Mato Grosso do Sul, Brasl \\ cleiton.biouems@gmail.com \\ Danielly Pereira da Silva \\ Bacharel em Gestão Ambiental, Universidade Estadual de Mato Grosso do Sul, Brasil \\ silvap19981@gmail.com
}

\begin{abstract}
Resumo
A água é um recurso de importância estratégica para o desenvolvimento sustentável, sua extração sem controle e a degradação da sua condição de qualidade, exige medidas de planejamento e avaliação constante, principalmente ao nível de microbacia que permite a realização de ações de manejo com maior celeridade. Assim, o presente trabalho teve como objetivo identificar o perfil hidroambiental da microbacia do Córrego Criminoso no município de Coxim/ MS e a sua condição de balneabilidade. $\mathrm{O}$ estudo foi realizado em dois pontos, sendo um a montante e o outro a jusante do perímetro urbano entre os meses de abril a outubro de 2018. Os parâmetros analisados foram: Demanda Bioquímica de Oxigênio $\left(\mathrm{DBO}_{5,20}\right)$, Coliformes Totais (CT), Escherichia coli (EC), Fosforo Total (FT), Potencial Hidrogeniônico (pH), Turbidez (TU), Sólidos Totais (ST), Cor (C), Oxigênio Dissolvido (OD), Alcalinidade (A), Temperatura da Amostra (T). Os resultados obtidos foram comparados com a Resolução CONAMA 274/2000 e 357/2005, demostrando alterações e desconformidades nas análises microbiológicas e DBO. Concluiu-se, portanto, que o perfil hidroambiental foi capaz de mostrar os aspectos ambientais responsáveis pela deterioração da qualidade da água ao longo do Córrego Criminoso.
\end{abstract}

Palavras-chave: lazer, contaminação, segurança hídrica.

\begin{abstract}
Water is a resource of strategic importance for sustainable development, its uncontrolled extraction and the degradation of its quality condition, demand constant planning and evaluation measures, mainly at the level of the watershed that allows for faster management actions. The aim of this study had to identify the hydro - environmental profile of the Criminoso's stream micro basin in the county Coxim / MS and its bathing condition. The study was performed in two points, one upstream and the other downstream from the urban perimeter between April and October 2018. The parameters analysed were: Biochemical Oxygen Demand (BOD5,20), Total Coliforms (TC), Escherichia coli (EC), Total Phosphorus (TP), Potential Hydrogen (pH), Turbidity (TU), Total Solids (TS), Color (C), Dissolved Oxygen (DO), Alkalinity (A) sample temperature (T). The results obtained were compared with CONAMA's resolves 274/2000 and 357/2005, showed alterations and nonconformities in the microbiological and BOD analyses. It was concluded, therefore, that the hydro-environmental profile was able to show off the environmental aspects responsible for the deterioration of water quality along the Criminoso's Stream.
\end{abstract}

Keywords: recreation, contamination, water security. 


\section{INTRODUÇÃO}

A intensa exploração dos recursos naturais, o uso inadequado do solo, o avanço de áreas de cultura aumentando desmatamento e o crescimento das cidades tem provocado inúmeros problemas ambientais, principalmente em áreas próximo a nascentes repercutindo negativamente na qualidade da água. (WILSON E WENG, 2011; LUBENOW et. al., 2012; OLIVEIRA FILHO et. al., 2012)

Além disso, as características geomorfológicas e o uso e ocupação da bacia, podem resultar em alterações na quantidade das águas pluviais, que por sua vez pode modificar as características físicas, químicas e biológicas do corpo hídrico receptor desse escoamento (SILVA et. al., 2010). De tal modo, faz-se necessário o estudo das interações da qualidade da água e das ações antrópicas no uso do solo na bacia hidrográfica, tendo em vista que a conservação da água depende da conservação dos outros recursos naturais da bacia de contribuição (ZUFFO et. al., 2013).

A água é uma substância química essencial nos processos biológicos de manutenção da vida na Terra e de produção de bens de consumo. Dotado de valor econômico, este bem ganhou destaque no cenário mundial com a preocupação em torno da disponibilidade qualitativa e quantitativa para a atual e futura geração (REZENDE, 2003).

O aumento da urbanização e densidade populacional nas cidades tem exercido pressão sobre este recurso natural, isto porque os corpos hídricos são frequentemente utilizados como receptores de esgoto bruto e resíduos sólidos domésticos, industriais e agrícola, comprometendo os seus usos múltiplos, sobretudo a prática de recreação de contato primário (LOPES et al., 2015).

As águas destinadas a atividades recreativas de contato primário requerem condições específicas de qualidade, ou seja, devem obedecer a padrões determinados de balneabilidade conforme a resolução CONAMA 274/2000 que enquadra como próprios ou impróprios com base em dados estatísticos os corpos d'água; e a de acordo com a resolução CONAMA 357/2005 que associa a qualidade da água ao seu uso possível (AMARAL, 2017; BRASIL, 2005; BRASIL, 2000).

Assim, segundo Campos e Cunha (2013) a balneabilidade é uma importante ferramenta de controle da qualidade ambiental, pois permiti a fiscalização e verificação das águas, reduzindo o risco da exposição direta e constante de organismos patogênicos capazes de comprometer a saúde humana, e a condição de qualidade do meio ambiente.

Nos mananciais superficiais as alterações no seu comportamento ocorrem principalmente por influência do uso e ocupação, sendo o monitoramento um instrumento primordial no planejamento ambiental estratégico (VASCO et al., 2011). 
A bacia hidrográfica é a unidade que melhor possibilita a gestão dos recursos hídricos por considerar de forma integral as características físicas, econômicas e sociais, sendo a qualidade da água a sinergia dessas variáveis (MOURA et al., 2010).

Diante do exposto, o presente trabalho objetivou identificar o perfil hidroambiental da microbacia do Córrego Criminoso, no município de Coxim Mato Grosso do Sul e a sua balneabilidade. Integrando os dados de usos e ocupação da bacia de drenagem aos dados de qualidade da água, como subsídio ao planejamento e gestão de microbacias urbanas.

\section{MATERIAIS E MÉTODOS}

\section{1. Área de Estudo}

A microbacia do Córrego Criminoso possui uma área de 28 ha e $6.305 \mathrm{~m}^{2}$, localizada na Bacia Hidrográfica do Alto Paraguai, sub-bacia do Rio Taquari entre as coordenadas geográficas: $18^{\circ} 27^{\prime} 49,9^{\prime \prime}$ e $18^{\circ} 29^{\prime} 21^{\prime \prime} \mathrm{S}$, e $54^{\circ} 43^{\prime} 56,7^{\prime \prime}$ e 54 45' 13,9" W. Para as análises da condição de qualidade da água foram estabelecidos dois pontos de amostragem o ponto 1 à montante próximo a nascente e o ponto 2 a jusante próximo ao exutório da microbacia, conforme indicado na Figura 1.

O Córrego Criminoso é um importante afluente da margem direita do rio Taquari, o córrego possui $5,5 \mathrm{~km}$ de extensão e está sob forte influência da zona urbana do município de Coxim-MS, que está parcialmente inserido na microbacia, este aspecto influencia em seu comportamento devido ao escoamento superficial urbano e a eventuais lançamentos clandestinos de efluentes ao longo do seu curso (GUNTZEL et al., 2011; SOUZA \& RIBEIRO, 2016).

O clima da região de estudo segundo Köppen (2006) é classificado como tipo “ $A W$ ”, com inverno seco e verão chuvoso. O tipo de solo predominante são areias Quartzosas, de relevo plano e dissecado com alta taxa de erodibilidade. A fitofisionomia é de Savana Florestada, seguida de Savana/Floresta Estacional Semidecidual, tendo o uso da terra predominante para a região a agropecuária (GALDINO et al., 2003). 


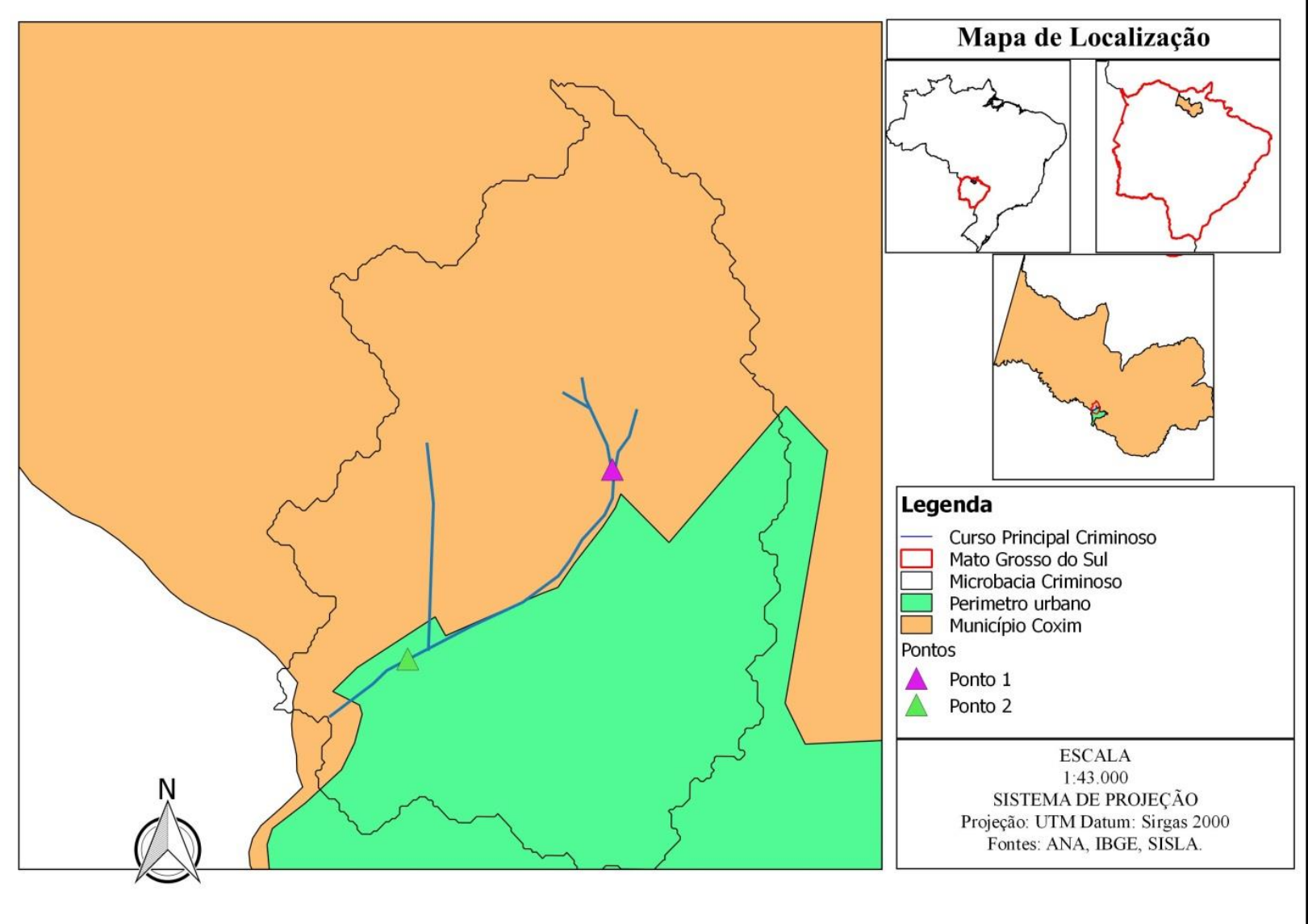

Figura 1 - Localização da microbacia do Córrego Criminoso e dos pontos de amostragem

Fonte: Elaborado pelos autores, 2019.

\subsection{Amostragem e método analítico}

Para medir a qualidade da água do Córrego Criminoso determinou-se dois pontos de amostragem ao longo do curso principal, sendo um a montante e outro a jusante do perímetro urbano. As coletas foram executadas mensalmente entre os meses de abril a outubro de 2018, totalizando seis, e uma campanha piloto. Os métodos de coleta, preservação e análise das amostras seguiram as técnicas descritas conforme APHA (2012).

O limite de detecção (LDM) e os procedimentos analíticos de cada parâmetro físico, químico e biológico estão definidos na Tabela 1. Além disso, na tabulação dos dados utilizou-se a planilha Microsoft Office/Excel 2007.

Tabela 1 - Métodos Analíticos empregados para cada parâmetro de acordo com APHA (2012).

\begin{tabular}{c|c|c|c}
\hline Parâmetro & Unidade & LDM & Método Analítico \\
Demanda Bioquímica de Oxigênio5,20 & $\mathrm{mg} \mathrm{L}^{-1} \mathrm{O}_{2}$ & 1,0 & SMEWW 5210 B \\
Coliformes Totais & UFC.100 ml & 1 & COLIPAPER - M048 A \\
Escherichia coli & UFC.100 ml & 1 & COLIPAPER - M048 A \\
Fosforo Total & $\mathrm{mg} \cdot \mathrm{L}^{-1} \mathrm{P}$ & 0,04 & SMEWW 4500-P D \\
Potencial Hidrogeniônico & - & $0-14$ & SMEWW 4500-H B \\
Turbidez & $\mathrm{UNT}$ & 0,1 & SMEWW 2130 B \\
Sólidos Totais & $\mathrm{mg} \cdot \mathrm{L}^{-1}$ & 10 & SMEWW 2540 \\
Oxigênio Dissolvido & $\mathrm{mg} \cdot \mathrm{L}^{-1} \mathrm{O}_{2}$ & 0,5 & SMEWW 4500-O C \\
Alcalinidade & $\mathrm{CaCO}_{3} \mathrm{~L}^{-1}$ & 5 & SMEWW 2320 B
\end{tabular}




$\begin{array}{cccc}\text { Cor } & \mathrm{uH} & 0,1 & \text { SMEWW 2130 B } \\ \text { Temperatura da Amostra } & { }^{\circ} \mathrm{C} & 0,5 & \text { SMEWW 2550 B }\end{array}$

\section{3. Índice de Balneabilidade}

Na aplicação do índice de balneabilidade considerou-se a quantidade de bactérias do grupo E. Coli estabelecidos na resolução CONAMA 274/2000. O cálculo utilizado para classificar as águas destinas as atividades de contato primário leva em consideração as 5 últimas campanhas, variando de excelente a imprópria, conforme mostra a Tabela 2. Contudo, para análise dos parâmetros físico-químicos utilizou-se a CONAMA 357/2005 (Tabela 3).

Tabela 2 - Classificação dos corpos d'águas de acordo com aplicação do índice de balneabilidade CONAMA 274/ 2000 .

\begin{tabular}{ccc}
\hline \multirow{2}{*}{ Classificação } & \multicolumn{2}{c}{ Escherichia coli } \\
\cline { 2 - 3 } & Categoria & UFC. $100 \mathrm{ml}^{-1}$ ou NMP.100 $\mathrm{ml}^{-1}$ \\
\hline \multirow{2}{*}{ Própria } & Excelente & Máximo de 200 \\
& Muito Boa & Máximo de 400 \\
& Satisfatória & Máximo de 800 \\
Imprópria & Superior a $800 \mathrm{em}$ mais de $20 \%$ do tempo ou 2000 na última análise \\
\hline
\end{tabular}

Tabela 3 - Padrões estabelecidos pela Resolução CONAMA 357/2005.

\begin{tabular}{ccc}
\hline Parâmetro & Padrão Classe 2 & Unidade \\
\hline Temperatura (T) & - & ${ }^{\circ} \mathrm{C}$ \\
Potencial Hidrogeniônico (pH) & 6 à 9 & - \\
Oxigênio Dissolvido (OD) & $>=5$ & $\mathrm{mg} \mathrm{L}^{-1} \mathrm{O}_{2}$ \\
Demanda Bioquímica de Oxigênio $\left(\mathrm{DBO}_{5,20}\right)$ & 5 & $\mathrm{mg} \mathrm{L}^{-1} \mathrm{O}_{2}$ \\
Coliformes Totais (CT) & - & ${\mathrm{UFC} 100 \mathrm{ml}^{-1}}^{-1}$ \\
Escherichia coli $($ E. coli) & 1.000 & ${\mathrm{UFC} 100 \mathrm{ml}^{-1}}^{-1} \mathrm{mg} \mathrm{L}^{-1} \mathrm{P}$ \\
Fósforo Total (FT) & 0,1 & $\mathrm{mg} \mathrm{L}^{-1}-$ \\
Sólidos Totais (ST) & 500 & $\mathrm{CaCO}_{3} \mathrm{~L}^{-1}-$ \\
Alcalinidade (Alc) & - & $\mathrm{mg} \mathrm{Pt} \mathrm{L}^{-1}$ \\
Cor & - & $\mathrm{UNT}^{-}$ \\
Turbidez (Turb) & 100 &
\end{tabular}

\subsection{Perfil Hidroambiental}

Na composição do perfil hidroambiental realizou-se visitas a campo para determinar com auxílio do GPS Status os pontos de coletas e observações, ao longo da microbacia do córrego Criminoso, a quantidade de demarcações obtida ao final totalizou 9.

Das nove demarcações duas referem aos pontos de coleta de amostras de água e as outra sete demostram as principais pressões antrópicas identificadas na área de estudo. Essas demarcações serviram de base para analisar o uso e ocupação do solo da microbacia e para a obtenção de registros fotográficos dos pontos demarcados, para serem adicionados ao mapa. 
A delimitação da microbacia foi obtida conforme descrito por NETELER \& MITASOVA (2013), através de um raster srtm com os dados de elevação e aplicação do algoritmo r.watershed no software Quantum Gis, após extraída a rede de drenagem do curso principal, aplicou-se o algoritmo r.water.outlet para determinar a área da microbacia de estudo. Empregou-se a ferramenta Terrain profile na aquisição do perfil de elevação e o compositor de mapas do Qgis para produzir o mapa, de acordo com Barbosa (2013).

\section{5. Estatística}

Foi realizada a estatística descritiva dos parâmetros de qualidade da água com o auxílio do programa XLSTAT 2018.5.51886, os dados de cada parâmetro foram agrupados por estação hidrológica. O Período seco compreendeu os meses de Maio a Agosto, e o período chuvoso os meses de Abril e Outubro. Através da estatística descritiva foi possível determinar o valor mínimo, máximo, médio e o desvio padrão de cada variável de qualidade de água analisada, permitindo a sua comparação aos padrões estabelecidos pelas resoluções CONAMA 274/2000 e CONAMA $357 / 2005$.

\section{RESULTADOS E DISCUSSÕES}

\subsection{Análise do Índice de Balneabilidade}

O córrego Criminoso está enquadrado como classe 2 de acordo com o art. 42 da resolução CONAMA 357/2005. Assim para avaliar a condição de qualidade da água do córrego e sua balneabilidade o comportamento das variáveis analisadas considerando o a estação seca (maio a agosto) e chuvosa (abril e outubro) foi comparada com os valores máximos permitidos para cada parâmetro nas resoluções CONAMA 274/2000 (balneabilidade) e CONAMA 357/2005 (qualidade da água). O comportamento das variáveis de qualidade da água pode ser observado na tabela 4.

Observa-se, dentro do período analisado, que os parâmetros físicos cor, turbidez, temperatura e sólidos totais, apresentaram pouca diferença entre a região de montante e jusante, com variação nos meses de maior pluviosidade, período de maior interferência do escoamento superficial na microbacia, todavia sem que os valores médio e máximo de turbidez e resíduo total ultrapassassem os limites legais. Este comportamento deve-se possivelmente ao perfil geomorfológico e climático da região e a vazão do curso d'água. Para Richter (2009), isso é consequência da lavagem da área de drenagem pela precipitação, que transporta o material particulado aos mananciais superficiais, interferindo nas concentrações dos parâmetros físicos. 
Tabela 4 - Resultado Estatístico das análises Escherichia Coli (EC) e Coliformes Totais, Cor (C), Turbidez (TU), Fósforo Total (FT), Potencial Hidrogeniônico (pH), Alcalinidade (Alc), Sólidos Totais (ST), Oxigênio Dissolvido (OD), Demanda Bioquímica de Oxigênio $\left(\mathrm{DBO}_{5,20}\right)$, Temperatura da Amostra (T).

\begin{tabular}{|c|c|c|c|c|c|c|c|c|c|}
\hline \multirow[b]{2}{*}{ Ponto } & \multirow[b]{2}{*}{ Parâmetro } & \multicolumn{4}{|c|}{ Estação Seca } & \multicolumn{4}{|c|}{ Estação Chuvosa } \\
\hline & & Mínimo & Máximo & Média & $\begin{array}{l}\text { Desvio- } \\
\text { padrão }\end{array}$ & Mínimo & Máximo & Média & $\begin{array}{l}\text { Desvio- } \\
\text { padrão }\end{array}$ \\
\hline \multirow{11}{*}{1} & E. Coli & $8.000,00$ & $36.000,00$ & $16.695,25$ & $11.269,39$ & $2.080,00$ & $8.000,00$ & $5.040,00$ & $2.960,00$ \\
\hline & CT & $16.000,00$ & $64.800,00$ & $34.022,50$ & $18.710,68$ & $6.800,00$ & $16.000,00$ & $11.400,00$ & $4.600,00$ \\
\hline & $\mathrm{C}$ & 3,40 & 11,20 & 6,60 & 2,92 & 5,20 & 10,40 & 6,93 & 2,45 \\
\hline & $\mathrm{TU}$ & 4,10 & 14,30 & 7,53 & 4,07 & 4,60 & 12,30 & 8,37 & 3,15 \\
\hline & FT & 0,00 & 0,09 & 0,04 & 0,04 & 0,00 & 0,00 & 0,00 & 0,00 \\
\hline & $\mathrm{pH}$ & 6,60 & 7,10 & 6,90 & 0,19 & 6,20 & 6,70 & 6,40 & 0,22 \\
\hline & Alc & 0,00 & 445,38 & 222,69 & 165,98 & 0,00 & 445,38 & 247,43 & 185,16 \\
\hline & $\mathrm{ST}$ & 68,00 & 120,00 & 88,75 & 20,04 & 98,00 & 130,00 & 112,00 & 13,37 \\
\hline & OD & 6,40 & 6,80 & 6,55 & 0,17 & 6,30 & 6,70 & 6,50 & 0,16 \\
\hline & DBO & 2,20 & 4,20 & 3,30 & 0,77 & 2,00 & 18,50 & 7,83 & 7,55 \\
\hline & $\mathrm{T}$ & 24,10 & 28,30 & 26,55 & 1,60 & 23,10 & 28,00 & 25,10 & 2,10 \\
\hline \multirow{11}{*}{2} & E. Coli & 16.000 & 79.200 & 34.874 & 25.777 & 3.600 & 16.000 & 9.800 & 6.200 \\
\hline & $\mathrm{CT}$ & 32.000 & 180.000 & 83.000 & 57.784 & 3.200 & 16.000 & 9.600 & 6.400 \\
\hline & $\mathrm{C}$ & 5,40 & 15,40 & 8,58 & 4,01 & 3,00 & 13,60 & 7,17 & 4,61 \\
\hline & $\mathrm{TU}$ & 5,80 & 22,20 & 10,50 & 6,81 & 3,00 & 16,40 & 10,43 & 5,57 \\
\hline & FT & 0,00 & 0,05 & 0,01 & 0,02 & 0,00 & 0,13 & 0,04 & 0,06 \\
\hline & $\mathrm{pH}$ & 6,00 & 6,70 & 6,38 & 0,29 & 5,80 & 5,90 & 5,83 & 0,05 \\
\hline & Alc & 593,84 & $1.336,13$ & $1.113,45$ & 306,05 & 890,76 & $1.781,51$ & $1.336,13$ & 363,65 \\
\hline & $\mathrm{ST}$ & 88,00 & 230,00 & 143,00 & 54,05 & 73,00 & 189,00 & 138,67 & 48,58 \\
\hline & OD & 6,80 & 7,30 & 7,10 & 0,19 & 6,90 & 7,60 & 7,17 & 0,31 \\
\hline & DBO & 1,40 & 4,90 & 3,20 & 1,35 & 2,00 & 8,20 & 4,27 & 2,79 \\
\hline & $\mathrm{T}$ & 24,60 & 28,60 & 26,40 & 1,43 & 23,60 & 28,90 & 26,17 & 2,17 \\
\hline
\end{tabular}

O oxigênio dissolvido apresentou-se dentro da conformidade legal, no Ponto 2, isso pode ser explicado pela existência de corredeiras. Segundo Agudo (1992) a absorção do Oxigênio Dissolvido na massa d’água depende das características hidráulicas proporcionais à velocidade, ou seja, a taxa de reaeração de uma queda d’água é maior do que em um trecho sem perturbação no rio.

Além disso, a alcalinidade, apesar de não possuir padrão estabelecido, serve de base na identificação de fontes poluição, exibindo valor $5 x$ maior no ponto 2 comparativamente ao ponto 1 . Baird (2002) correlaciona a alcalinidade ao grau de decomposição da matéria orgânica, consumindo o oxigênio dissolvido e deteriorando ambientes aquáticos. Rojas e Rocha (2004) argumenta o prejuízo aos peixes das altas concentrações destes íons na água.

$\mathrm{O}$ parâmetro $\mathrm{pH}$ manteve-se dentro dos padrões exigidos pela legislação no Ponto 1 e 2, porém manifestando caráter mais ácido no ponto 2, principalmente na estação chuvosa. Este comportamento retrata as ações antrópicas praticadas no trecho de águas mais ácidas, como observado por Pinto et al. (2009). Não se pode descartar o provável aumento de substâncias húmicas em decorrência da pluviosidade, promovendo o consumo de oxigênio dissolvido no 
processo de estabilização da matéria orgânica, além disso, devem-se considerar eventuais contribuições do perímetro urbano (SANTOS et al., 2017).

O parâmetro fósforo é um importante indicador das características do escoamento superficial da área de drenagem e de eventuais lançamentos clandestinos de esgoto, esta variável apresentou regularidade em ambos os pontos, aspecto ligado ao uso e ocupação da bacia e a autodepuração do corpo d'água. Entretanto, no período chuvoso, ocorreu um pequeno aumento nas concentrações de fósforo no ponto 2, o que de acordo com Sharpley et al. (1992) depende da duração, intensidade e intervalo de tempo da precipitação.

Em contrapartida ao exposto, a DBO seguiu a linha contraria dos demais parâmetros, em que se observou desconformidade apenas P1 no período chuvoso. A alta da DBO neste ponto pode estar relacionada ao remanescente vegetal próximo a nascente podendo ser efeito do acúmulo de matéria orgânica de processos naturais de perca das folhas, caules e raízes das árvores (ESTEVES, 2011).

As análises microbiológicas foram sem dúvida, o parâmetro de maior discrepância comparado ao padrão legal para recreação de contato primário. Ao aplicar o Índice de Balneabilidade constou-se que a água do Córrego Criminoso, pelo menos nos pontos aferidos, encontra-se imprópria em tempo igual ou superior a 50\% do ano, sendo o ponto mais crítico o que recebe influência da área urbana do município de Coxim, apresentando em média o dobro do valor da concentração de E.coli, comparativamente ao ponto 1, com uma pequena diluição na concentração de desse parâmetro do período chuvoso devido ao aumento do volume de água do corpo hídrico, conforme mostra a tabela 5.

Tabela 5: Resultados das análises microbiológicas do grupo E.coli de cada ponto de coleta, em UFC. $100 m L^{-1}$

\begin{tabular}{ccccc}
\cline { 2 - 3 } & P1 & P2 & \multicolumn{1}{c}{} \\
\cline { 2 - 3 } Abril & - & - & Legenda \\
Maio & 2080 & 3600 & Excelente \\
Junho & 8000 & 16000 \\
Julho & 10080 & 19600 & Muito Bom \\
Agosto & 12701 & 24696 & Satisfatório \\
Setembro & 36000 & 79200 & Impróprio \\
Outubro & 8000 & 16000 & \\
\hline
\end{tabular}

Fonte: Autores (2019).

Segundo Ribeiro e Rooke (2010) esse comportamento da variável microbiológica pode ser reflexo da insuficiência do esgotamento sanitário despejando diariamente nos corpos d’água os despejos sólidos e líquidos das cidades, e ainda não se pode descartar as contribuições trazidas pelo escoamento superficial da bacia de contribuição. A ausência de saneamento ambiental aumenta a 
proliferação das bactérias do grupo E.coli, o que restringe o uso da água para atividades de contato primário.

\subsection{Perfil Hidroambiental}

De acordo com o perfil hidroambiental (Figura 2) construído a partir da coleta de amostras de água e de dados em campo, identificou-se na região da nascente do Córrego Criminoso, uma área com considerável remanescente florestal, porém com presença de atividades agropecuárias predominando a plantação de eucalipto e a pecuária extensiva de corte.

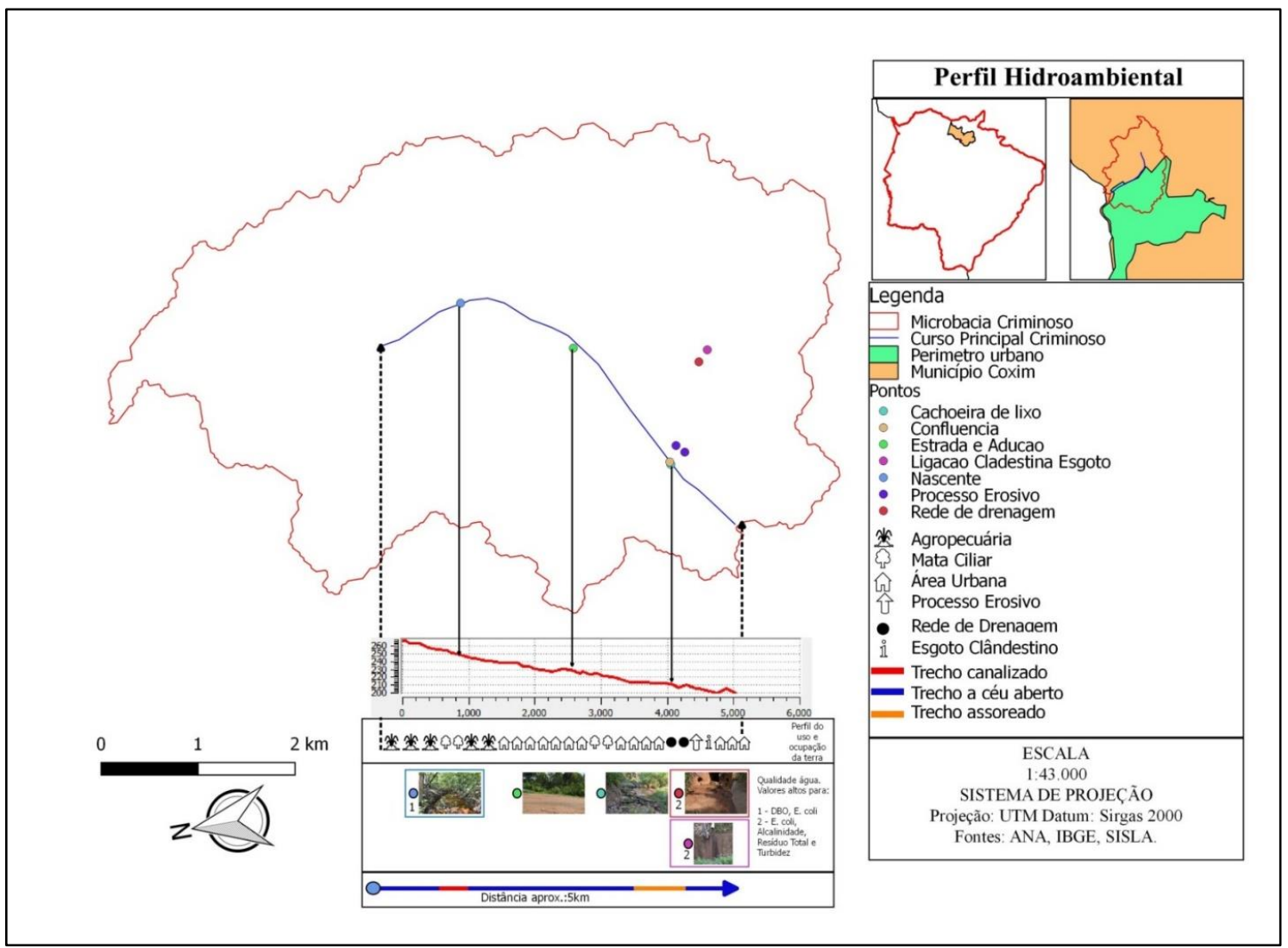

Figura 2 - Perfil Hidroambiental do Córrego Criminoso, Coxim- MS.

Fonte: Elaborado pelos autores, 2019.

Na figura 2 é possível verificar que o ponto 2 destacou-se os parâmetros DBO e E.coli com valores médios acima do estabelecido pelas resoluções, constatando comportamentos distintos entre os períodos hidrológicos para ambos os pontos de amostragem de qualidade da água, sendo que a DBO teve as suas concentrações aumentadas nos meses de chuva e a contaminação microbiológica teve aumento durante a estação seca, por consequência da redução da vazão do curso d'água.

Esse comportamento da DBO ocorre sempre que a diluição provocada pelo aumento da vazão no período chuvoso é insuficiente para reduzir sua concentração (VASCO et al., 2011). E ainda a chuva é um agente transportador de matéria orgânica, enriquecendo as águas e 
desequilibrando os processos de fotossíntese e decomposição conforme CETESB (2018). Além disso, para Franco et al. (2007) a diminuição do volume de água no período seco e o despejo de esgoto bruto intensifica a proliferação de bactérias do grupo coliformes.

Ao longo do córrego a existência de estrada e adução de água está acelerando o processo erosivo e a entrada de sedimentos nos cursos d’água, como também interferindo na vazão. Desse modo, Cunha et al. (2013) em seu estudo afirma que a falta ou a execução errônea de dissipadores nas estradas rurais potencializa a introdução de sedimentos e erosão. A captação irregular, segundo a ANA (2012) afeta o planejamento, podendo gerar falta de água devido à má utilização, e influenciar alguns dos usos múltiplos deste recurso.

No trecho de maior proximidade com a zona urbana fica evidente a pressão antrópica, observado na quantidade de resíduo nas margens e no próprio regato, bem como nas ligações clandestinas das residências.

Assim as variáveis envolvidas na deterioração da água na região em questão são a alcalinidade, sólidos totais, turbidez e E.coli, efeito do escoamento superficial, da contribuição da rede de drenagem urbana e dos dois grandes processos erosivos. Esse fato comprova os resultados encontrados na aplicação do índice de balneabilidade, que demostraram o P2 como o ponto mais contaminado, principalmente a respeito das análises bacteriológicas.

Para Cornelli et al. (2016) a maneira como a humanidade ocupa o solo está ligado á qualidade da água, sendo os piores resultados dos parâmetros analisados na área de maior intervenção antrópica. Melo et al. (2002) identificou a área urbana o maior contribuinte na contaminação de origem fecal, acentuada nos últimos doze meses pelo crescimento populacional nas margens do Rio.

\section{CONSIDERAÇÕES FINAIS}

As pesquisas de aspectos ambientais como a qualidade da água para balneabilidade possuem grande importância para a sociedade, principalmente por tratar-se de um recurso estratégico e insubstituível com a água, utilizada muitas vezes de forma indiscriminada e potencializando a degradação da sua condição de qualidade.

Portanto, o presente artigo contribui de forma significativa para fornecer ferramentas eficientes e pouco dispendiosas para servir de base ao planejamento de ações estratégicas voltadas a preservação da qualidade da água.

O perfil hidroambiental mostrou-se uma ferramenta útil e de baixo custo para a avaliação da qualidade da água superficial ao nível de microbacias, auxiliando a identificação das pressões bem como das potenciais medidas de controle ambiental. 
O córrego Criminoso apresentou uma tendência de poluição orgânica identificada no parâmetro DBO na região da nascente do curso d'água, por consequência das atividades agropecuárias desenvolvidas na região.

Os resultados evidenciaram problemas de saneamento básico na microbacia com o aumento expressivo da contaminação microbiológica no ponto 2 após a contribuição do perímetro urbano.

Outro fato evidenciado no estudo foi à influência da pluviosidade na variação dos parâmetros sólidos totais, turbidez e alcalinidade no período de pluvioso.

O córrego criminoso apresentou-se impróprio para a recreação de contato primário, com inconformidades em ambos os pontos de amostragem ao longo de todas as campanhas analisadas, sobretudo no ponto 2 após a influência urbana.

Medidas de planejamento e gestão devem ser adotadas na microbacia, para evitar o avanço do processo de degradação da qualidade da água e comunicar a comunidade os riscos do contato direto com as águas do córrego.

\section{REFERÊNCIAS}

ANA - AGÊNCIA NACIONAL DAS ÁGUAS. Panorama da qualidade das águas superficiais do Brasil. 1. ed. Brasília: ANA, 2012. 264p.

AGUDO, E. G. Demanda Bioquímica de Oxigênio. Curso Fundamentos Químicos do Saneamento. Universidade Mackenzie, 1992.

AMARAL, B. G. Avaliação Ambiental do Índice de Balneabilidade da Praia do Açutuba, Iranduba - Amazonas. Revista Especialize On-line IPOG, Goiânia, v. 1, n. 14, p. 2, 2017.

APHA - American Public Health Association; AWWA - American Water Works Association; WEF - Water Environment Federation, Standart methods for the examination of water and wasterwater. 22 ed. Washington, DC: American Public Health Association, 2012. 1220p.

APHA - American Public Health Association; AWWA - American Water Works Association;

BAIRD, C. Química Ambiental. 2 ed. Porto Alegre: Bookman, 2002. 622p.

BARBOSA, F. D. Perfil hidroambiental da microbacia do córrego Nova Rincão. Rincão/SP. In: WORKSHOP INTERNACIONAL SOBRE PLANEJAMENTO E DESENVOLVIMENTO SUSTENTÁVEL EM BACIAS HIDROGRÁFICAS. 4., 2013, Presidente Prudente. Anais... Presidente Prudente: UNESP, 2013. p. 1671-1682.

BRASIL. CONAMA. CONSELHO NACIONAL DO MEIO AMBIENTE. Resolução $\mathbf{n}^{\circ}$ 274, de 29 de novembro de 2000. Disponível em: <http://www2.mma.gov.br/port/conama/legiabre. cfm?codlegi=272>. Acesso em: 08 set. 2018. 
BRASIL. CONAMA. CONSELHO NACIONAL DO MEIO AMBIENTE. Resolução $\mathbf{n}^{\circ}$ 357, de 17 de março de 2005. Disponível em: Disponível em: <http://www2.mma.gov.br/port/ conama/legiabre. cfm?codlegi=459> . Acesso em: 08 set. 2018.

CAMPOS, J. S; CUNHA, H. F. A. Análise Comparativa de Parâmetros de Balneabilidade em Fazendinha, Macapá-AP. Biota Amazônia. Macapá, v. 5, n. 4, p. 110-118, 2015.

COMPANHIA AMBIENTAL DO ESTADO DE SÃO PAULO (CETESB). Mortandade de Peixes. Disponível em: <https://cetesb.sp.gov.br/mortandade-peixes/alteracoes-fisicas-equimicas/materia-organica-e-nutrientes/ > . Acesso em: 01 out. 2018.

CORNELli, R.; SCHNEIDERT, V. E.; BORTOLIN, T. A.; CEMIN, G. T.; SANTOS, G. M. Análise da Influência do Uso e Ocupação do Solo na Qualidade da Água de Duas Sub-Bacias Hidrográficas do Município de Caxias do Sul. Scientia cum Industria, v. 4, n. 1, p. 1-14, 2016.

CUNHA, M. C.; THOMAZ, E. L.; VESTENA, L. R. Medidas de Controle de Erosão em Estradas Rurais na Bacia do Rio das Pedras, Guarapuava-PR. Sociedade \& Natureza, Uberlândia, v. 25, n. 1, p. 107-118, 2013.

ESTEVES, F. A. Fundamentos de Limnologia. 3. ed. Rio de Janeiro: Interciência, 2011. 826p.

FRANCO, R. A. M.; HERNANDEZ, F. B. T.; VANZELA, L. S. "Utilização dos Parâmetros Coliformes Totais e Fecais e Oxigênio Dissolvido na Avaliação da Qualidade de Água para Irrigação. In: CONGRESSO BRASILEIRO DE ENGENHARIA AGRÍCOLA. 36., 2007, Bonito. Anais... Bonito. 2007. p. 1-4.

GALDINO S., VIEIRA L. M., SORIANO B. M. A. Erosão na Bacia do Alto Taquari. 1. ed. Corumbá: Embrapa Pantanal, 2003. 46p.

GUNTZEL, A. M.; DIAS, N. R.; COERTJENS, C. M.; SILVA, G. C. \& VIEIRA, E. A. Análise Fitossociológica de um Remanescente de Vegetação na Microbacia do Córrego Criminoso (Bacia do Rio Taquari, Coxim, MS, Brasil): subsídios para a recomposição da vegetação. Acta Botânica Brasilica, v. 25, n. 3, p. 586 - 592, 2011.

LOPES, F. W. A; VON SPERLING, E.; MAGALHAES JR, A. P. Indicadores para Balneabilidade em Águas Doces no Brasil. Geografias, v. 11, n.1 , p. 06-22, 2015.

LUBENOW, A. T.; OLIVEIRA FILHO, P. C.; VIDAL, C. M. S.; CAVALlinI, G. S.; CANTERLE, Y. C. Impacto do uso e ocupação da terra na qualidade da água da bacia hidrográfica do rio Nhapindazal, Irati (PR). Ambiência Guarapuava,v. 8, n. 3, p. 845-858, 2012.

MELO, D. C. P.; GAZINEU, M. H. P.; SILVA, J. C.; PAIVA, S. C.; REGO, R. C. P.; SAlguEIRO, A. A Influência das Condições da Maré na Qualidade de Água do Rio Formoso, Pernambuco. Revista Química \& Tecnologia, n. 1, p. 20-25, 2002.

MOURA, L.H.A.; BOAVENTURA, G.R.; PINELLI, M.P. A Qualidade de Água como Indicador de Uso e Ocupação do Solo: Bacia do Gama- Distrito Federal. Quimica Nova. v.33, n. 1, p. 97 $103,2010$.

NETELER, M; MITASOVA, H. Open source GIS: a GRASS GIS approach. 3. ed. Springer Science \& Business Media, 2013. 438p. 
OLIVEIRA FILHO, P. C.; DUTRA, A. M.; CERUTI, F. C. Qualidade das águas superficiais e o uso da terra: Estudo de caso pontual em bacia hidrográfica do oeste do Paraná. Floresta e Ambiente, v. 19, n. 1, p. 32-43, 2012.

PINTO, A. G. N.; HORBE, A. M. C.; SILVA, M. S.R.; MIRANDA, S. A. F.; PASCOALATO, D.; SANTOS, H. M. C. Efeitos da Ação Antrópica sobre a Hidrogeoquímica do Rio Negro na Orla de Manaus, AM. Acta amazonica, v. 39, n. 3. p. 627-638, 2009.

REZENDE, M. O.; ROSA, R. S.; MESSIAS, R. A.; AMBROZINI, B. Importância da Compreensão dos Ciclos Biogeoquímicos para o Desenvolvimento Sustentável. São Carlos: Instituto de química de São Carlos, 2003. 56p.

RIBEIRO, J. W.; ROOKE, J. M. S. Saneamento Básico e sua Relação com o Meio Ambiente e a Saúde Pública. 2010. 36 f. Monografia (Trabalho de Especialização em Análise Ambiental) Universidade Federal de Juiz de Fora, Juiz e Fora, 2010.

RICHTER, C. A. Água-Métodos e Tecnologia de Tratamento. 1. ed. São Paulo: Blucher, 2009. 340p.

ROJAS, N.E.T.; ROCHA, O. Influência da Alcalinidade da Água sobre o Crescimento de Larvas de Tilápia do Nilo. Acta Scientiarum. Biological Sciences, Maringá, v. 26, n. 2, p. 163 - 167, 2004.

SANTOS, C. O.; BROCH, S. A. O.; OLIVEIRA, K. R. F. Qualidade de águas superficiais da bacia hidrográfica transfronteiriça do rio Apa. In: SIMPÓSIO BRASILEIRO DE RECURSOS HÍDRICOS, 22., 2017, Florianópolis. Anais... Florianópolis: Abrh, 2017, p. 1-8.

SHARPLEY, A. N.; SMITH, S. J.; JONES, O. R.; BERG, W. A.; COLEMAN, G. A. The Transport of Bioavailable Phosphorus in Agricultural Runoff. Journal Environmental Quality, v. 21, p. 30$35,1992$.

SILVA, D. F.; GALVÍNCIO, J. D.; ALMEIDA, H. R. R. C. A qualidade de água na totalidade da bacia hidrográfica do rio São Francisco e suas causas, Espírito Santo do Pinhal. Revista de Engenharia Ambiental, v.7, n. 4, p. 133-151, 2010.

SOUZA, D. A. F.; RIBEIRO, M. L. Índice de Qualidade de Água - IQAcetesb do Rio Taquari , no Município de Coxim. Campo Grande : PIBIC, 2016

VASCO, A. N.; BRITTO, F. B.; PEREIRA, A. P. S.; MÉLlO JÚNIOR, A. V. M.; GARCIA, C. A. B.; NOGUEIRA, L. C. Avaliação Espacial e Temporal da Qualidade da Água na Sub-Bacia do Rio Poxim, Sergipe, Brasil. Revista Ambiente \& Água, Taubaté, v. 6, n. 1, p. 118-130, 2011.

WILSON, C. O.; WENG, Q. Simulating the impacts of future lan use and climate changes on surface water quality in the Des Plaines River watershed, Chicago Metropolitan Statical Area, Illinois. Science of the Total Environment, v. 409, p. 4387-4405, 2011.

ZUFFO, C. E.; NASCIMENTO, G. F.; ABREU, F. A. M.; CAVALCANTI, I. N. Caracterização da qualidade de águas superficiais em Rondônia, Anuário do instituto de Geociências, Rio de Janeiro v. 36, n. 2, p. 25-39, 2013. 